\title{
How lockdown causes a missing generation of start-ups and jobs
}

\author{
Shyngys Karimov ${ }^{1}$ D Jozef Konings ${ }^{1,2,3}$
}

Accepted: 6 August 2021 / Published online: 21 August 2021

(c) The Author(s), under exclusive licence to Springer-Verlag GmbH Germany, part of Springer Nature 2021

\begin{abstract}
This paper explores the impact of the COVID-19 lockdown on aggregate employment in Belgium. To this end, we use microdata of all Belgian firms and apply a machine learning-based approach to simulate the impact of the lockdown on employment growth under various economic scenarios. In doing so, we distinguish between start-ups and incumbent firms with both short and long-term effects. In the short term, we expect to see significant losses of employment coming mainly from mature incumbent firms. In the long term, the missing generation of start-ups formed during the lockdown will have a significant and growing effect of slowing down the employment growth even a decade after the lockdown.
\end{abstract}

Keywords Start-ups · Employment dynamics · COVID-19 · Machine learning

\section{Introduction}

Boosting job creation and job reallocation is a priority for policymakers following the health crisis of 2020 as the economies worldwide experience unprecedented job losses. Belgium went into its first lockdown on March 18th of 2020 to contain the coronavirus, with the mobility and social distancing restrictions persisting into 2021. While these extraordinary measures helped to slow down the spread of the virus and to prevent the overload of health services, they also affected the economy significantly. The National Bank of Belgium estimates an economic decline of $6.3 \%$ during 2020 in real terms. At the same time, the number of employed people in Belgium shrunk by 0.8 percentage points. While in the first quarter of 2021 the economy

Shyngys Karimov

shyngys.karimov@kuleuven.be

1 Department of Economics, VIVES, KU Leuven, Leuven, Belgium

2 Graduate School of Business, Nazarbayev University, Nur-Sultan, Kazakhstan

3 University of Liverpool Management School, Liverpool, UK 
grew by $0.6 \%$, the unemployment rate remained at elevated levels than before the pandemic. ${ }^{1}$

During the lockdown most of the measures to support the businesses and entrepreneurship went to incumbent firms, ignoring to large extent start-up firms. However, a small group of these start-ups is high-growth firms that matter for innovation, creative destruction, and productivity growth in the long run (Acemoglu and Cao 2015; Aghion et al. 2009; Decker et al. 2017, 2016; Sterk et al. 2021). According to the National Social Security Office of Belgium, the entry of new firms in the private sector during the first half of 2020 relative to the first half of 2019 decreased by $40 \%$. This number is even higher for start-ups with employment. While in the second half of 2020 the start-up activity picked up slightly, nonetheless, it remained below the pre-crisis level. Karimov and Konings (2020) show that the start-ups in Belgium are net job creators in the long term. Therefore, a missing generation of start-ups would create a long-lasting impact on employment.

Despite the rapid development of vaccines, the restrictions are being lifted slowly and the supply chains will continue to be disrupted worldwide for a while, preventing firms from resuming business as usual. This has triggered a recession in 2020 for a small and open economy, such as Belgium. Pugsley and Şahin (2019) show that the survival rate and the conditional employment growth rate of incumbent firms are highly sensitive to business cycle fluctuations. Moreover, the studies suggest that the initial conditions of firms at the start-up phase matter a lot for their post-entry growth dynamics (Sedláček and Sterk 2017; Sterk et al. 2021). The COVID-19 pandemic affected significantly both, the business cycle and the conditions that firms operate in. Therefore, the employment gap generated by the lockdown has two components, the short-term and long-term effects, which need to be taken into account.

To this end, we assess the impact of the COVID-19 lockdown on jobs in Belgium using a dynamic decomposition framework as in Karimov and Konings (2020), but instead of holding sectors' age-specific survival rate and conditional growth rates at their averages, using machine learning algorithms, we predict them as a function of GDP growth, to forecast the evolution of aggregate employment under various economic scenarios. We consider two cases, the baseline and the lockdown, for the period of 2020-2030. The baseline case presents a counterfactual scenario without the COVID-19 pandemic. Here, we assume the economy to evolve as in the pre-crisis period. The lockdown case presents the actual case where GDP growth and startup rate decline sharply. Therefore, looking at the differences between the lockdown and baseline cases, we isolate the impact of lockdown on employment in Belgium. To this end, we use data on employment from the social security registry, which covers all firms with paid employment. We only focus on employment in private firms and consider full-time equivalent employment.

Our contribution is threefold. First, using the most recent data from the social security registry we describe the immediate effects of the first COVID-19 lockdown on the employment of Belgium. During the first half of 2020, the number of

\footnotetext{
1 According to the National Bank of Belgium, the unemployment rate in February 2021 is $5.7 \%$ and it used to be $4.9 \%$ in March 2020.
} 
private-sector jobs declined by almost $20 \%$ relative to the first half of 2019 . In the second half of 2020, the number jobs partially recovered leaving an employment gap of $6 \% \mathrm{Y}-\mathrm{O}-\mathrm{Y}$. While mature (ages $6+$ years) firms were responsible for $90 \%$ of lost jobs in absolute terms, the start-up and young firms experienced the highest employment losses (peaking at 47 and $30 \% \mathrm{Y}-\mathrm{O}-\mathrm{Y}$ ) in relative terms. Recent literature highlights the heightened sensitivity of young firms to business cycle fluctuations (Konings and Yergabulova 2021; Pugsley and Şahin 2019). Looking within sectors, the distribution sector (NACE 44-56) was impacted the most. It accounted for more than a half of lost jobs overall and $75 \%$ of firm exit during this period. Karimov and Konings (2020) show that the employment growth of the distribution sector in Belgium is primarily driven by the entry of new firms, and therefore the lockdown restrictions severely limit the entry margin for firms in distribution.

Second, we develop a machine learning-based approach to forecast the evolution of aggregate employment. The approach relies on the dynamic decomposition framework as in Pugsley and Şahin (2019) and the sectoral decomposition as in Karimov and Konings (2020). We extend it by using machine learning algorithms to predict the out-of-sample age-specific survival and conditional growth rates within narrowly defined industries based on business cycle fluctuations. This "from micro to macro" approach forecasts well the path of aggregate employment over time through the endogenous shifts in the age distribution and the sectoral composition of firms. As it incorporates expectations about the growth of the economy and allows us to perform a counterfactual analysis looking into the future, we simulate different values of the GDP growth and the start-up rate. Therefore, we use it as a simulation tool to estimate the impact of COVID-19 lockdown on the aggregate employment of Belgium. For the US, Sedlacek and Sterk (2020) build their model upon the number of start-ups, their size upon entry, and survival rate of young firms to quantify the aggregate employment losses. However, they ignore the sensitivity of incumbent firms to business cycle fluctuations, and we show that such effects are very important, especially in the short term.

Third, we forecast the impact of the COVID-19 pandemic on the aggregate employment of a small open economy, Belgium, during the period of 2020-2030. Under relatively mild assumptions, the forecasting results suggest that the lockdown has two types of effects on employment, the short and long term. In the short term, private firms cut employment by 40 thousand jobs or $2 \%$ of aggregate employment, of which about 30 thousand jobs are due to mature firms. In the long term, the coronavirus crisis creates an employment gap of 26 thousand jobs a decade after the lockdown, and the gap is expected to continue growing. The missing generation of start-ups due to the lockdown accounts for 12 thousand jobs or $46 \%$ of the overall employment gap in the long run. Looking within sectors, we expect the majority of lost jobs, in the long run, to be in services. Belgian firms in services have the highest post-entry employment growth dynamics (Karimov and Konings 2020). The industrial and distribution sectors are expected to recover employment losses within the next five to six years.

While the actual job losses in 2020 are much higher than the forecasting results suggest, it is important to keep in mind that our approach relies on historical relationships observed in the data which do not capture the unprecedented effects of the 
mobility and social distancing restrictions imposed in Belgium during that period. Therefore, the simulation results are more likely to be an under prediction of actual effects to see. Our results suggest that the cumulative employment losses for Belgium are $1.3 \%$ of total employment, where half of the losses are due to a missing generation of start-ups formed during 2020. In the US, Sedlacek and Sterk (2020) suggest that in the case of quick economic recovery the cumulative employment losses are around 2 million jobs (1.4\% of total nonfarm employment), similarly highlighting the sensitivity of start-ups to economic conditions. Therefore, the relative magnitude of employment gaps in Belgium and the US are comparable, highlighting the significant employment costs of the measures taken during the pandemic.

The remainder of the paper is organized as follows: Section 2 describes the methodology; Section 3 presents the details of the data; Section 4 validates the model predictions; Section 5 discusses the forecasting results; Section 6 provides the concluding remarks and policy implications.

\section{Methodology}

In this section, we present a machine learning-based approach to estimate the impact of COVID-19 lockdown on aggregate employment. This model allows users to incorporate their expectations about the growth of the economy and understand the impact of the lockdown on actual jobs and people. While this is not a structural model, it incorporates the literature on firm dynamics and business cycle fluctuations into a machine learning model based on historical data. Therefore, the obtained results are based on real relationships observed in the data and sound economic intuition.

The approach builds on the dynamic decomposition framework of Pugsley and Şahin (2019) and the sectoral decomposition of Karimov and Konings (2020). We further extend it using machine learning algorithms to predict the out-of-sample survival and conditional employment growth rates of age-cohorts within narrowly defined industries. Differentiating between age groups is motivated by the literature on firm dynamics, where young firms experience higher employment growth rates and lower survival rates than their mature counterparts (Geurts and Van Biesebroeck 2016; Haltiwanger et al. 2013; Lawless 2014). Similarly, differentiating between industries is motivated by the literature on structural transformation, where firms face different competition, regulation, and technology levels in different industries (Dent et al. 2016; Duarte and Restuccia 2010; Foster et al. 2006; Karimov and Konings 2020). Usage of machine learning algorithms is possible due to the availability of quarterly firm-level data covering the entire population of firms in Belgium for the 2003-2012 period.

\subsection{Dynamic framework}

Formally, the dynamics of aggregate employment $E$ over time $t$ can be written as the sum of total employment in each sector $j$ of the economy. The aggregate 
employment of sector $j$ can be split into the employment over age cohorts $a$. Hence, $E_{t}$ is given by

$$
E_{t}=\sum_{j} E_{t}^{j}=\sum_{j}\left(s_{t}^{j} S_{t}+\sum_{a>0} E_{t, a}^{j}\right),
$$

where $S_{t}$ is the sum of employment among firms of age zero $(a=0)$ at time $t$, or the start-up employment, $s_{t}^{j}$ is the share of start-up employment in sector $j$ at time $t$, or the sectoral composition of start-ups, and $E_{t, a}^{j}$ is the employment of age cohort $a$ in sector $j$ at time $t$. The latter term of Eq. 1 can be further written as

$$
E_{t, a}^{j}=x_{t, a}^{j}\left(1+n_{t, a}^{j}\right) E_{t-1, a-1}^{j},
$$

where $x_{t, a}^{j}$ is the survival rate of firms in sector $j$ in age cohort $a$ over the period $t-1$ and $t, n_{t, a}^{j}$ is the conditional growth rate of average employment size of age cohort $a$ over the period $t-1$ and $t$, and $E_{t-1, a-1}^{j}$ is the aggregate employment of the same cohort at time $t-1$. The product of a sector's age-specific survival and conditional growth rates is the unconditional employment growth rate of the sector's age-specific employment. Knowing the evolution of sectors' age-specific survival and conditional growth rates and the initial distribution of aggregate employment across age groups and sectors, this framework gives the exact evolution of aggregate employment over time.

\subsection{Business cycle fluctuations}

To capture the response of incumbent firms to business cycle fluctuations, we model the survival and conditional growth rates of age cohorts within industries as a function of business cycle fluctuations. Pugsley and Şahin (2019) show that the unconditional growth rate of young firms is higher than the one of mature firms. Therefore, the employment of young firms is more cyclical than the employment of mature firms. We use this idea to predict the employment response of incumbent firms within industries using machine learning. In particular, the survival rate of age cohort $a$ in sector $j$ at time $t$ is modeled as

$$
x_{t, a}^{j}=f_{x, a}^{j}\left(Z_{t}, \varepsilon_{x, t, a}^{j}\right)
$$

where $Z_{t}$ is a vector of past quarterly real GDP growth rates up to the period $t$, and $\varepsilon_{x, t, a}^{j}$ is a component of $x_{t, a}^{j}$ that cannot be predicted by $Z_{t}$. Similarly, the conditional growth rate of age cohort $a$ in sector $j$ at time $t$ is modeled as.

$$
n_{t, a}^{j}=f_{x, a}^{j}\left(Z_{t}, \varepsilon_{n, t, a}^{j}\right)
$$

where $\varepsilon_{n, t, a}^{j}$ is a component of $n_{t, a}^{j}$ that cannot be predicted by $Z_{t}$. Decomposed this way, the model allows for the variation in survival and conditional growth rates across age cohorts and industries as a function of business cycle. 


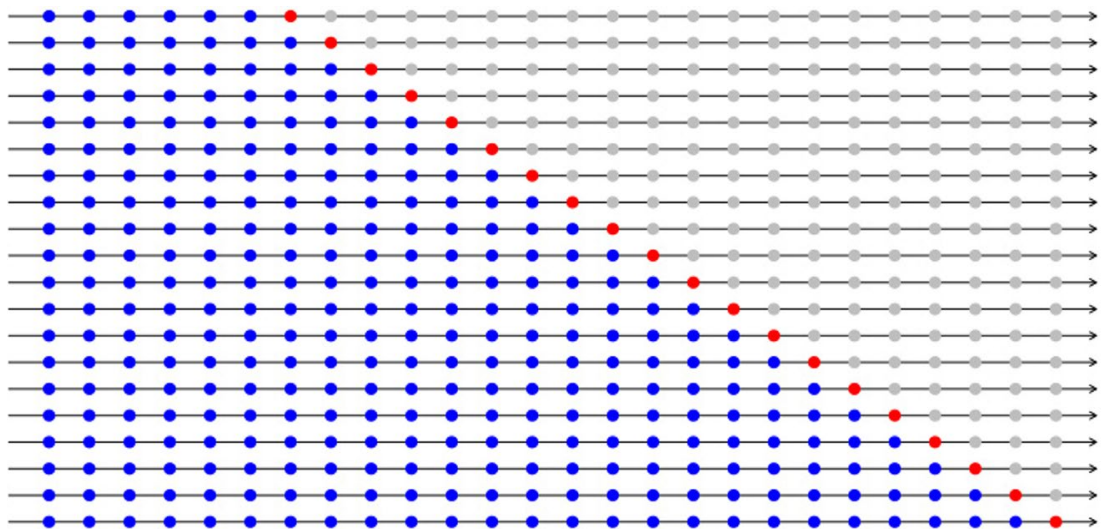

Fig. 1 The figure plots the cross validation strategy for training the machine learning model. The blue circles indicate the data to be used for training the model and the red circle indicates the data for testing the accuracy of the model

\subsection{Model selection}

While the models $f_{x, a}^{j}$ and $f_{n, a}^{j}$ can be any linear or non-linear functions of $Z_{t}$, we limit them to the set of standard workhorse models in machine learning literature. In particular, we consider linear regression, LASSO, ridge, elastic net, decision tree, random forest and boosted decision trees models (Hastie et al. 2009). Coupled together with the rich literature on employment dynamics and firm growth, these models provide high accuracy predictions. Later in the model validation section we provide the details of that.

To select the best models for predicting $x_{t, a}^{j}$ and $n_{t, a}^{j}$ we use time series cross validation. Figure 1 illustrates this strategy. We start by training the model on the early data and test its accuracy on the data one period ahead of the training sample. After the training sample gets expanded by one quarter ahead and the cycle repeats until we reach the last period of the data. The use of cross validation ensures that the models are not overfitting to the data and can be used for prediction out-of-sample. We repeat this process for all considered models and select the one that minimizes the average out-of-sample root mean squared error.

\subsection{Aggregation}

To forecast the evolution of aggregate employment over time we use

$$
\widehat{E}_{t}=\sum_{j}\left(\bar{s}_{t}^{j} S_{t}+\sum_{a>0} \widehat{f}_{x, a}^{j}\left(Z_{t}\right)\left[1+\widehat{f}_{n, a}^{j}\left(Z_{t}\right)\right] \widehat{E}_{t-1, a-1}^{j}\right),
$$

where $\hat{f}_{x, a}^{j}$ and $\hat{f}_{n, a}^{j}$ are the best models from model selection, the sectoral composition of start-ups $\bar{s}_{t}^{j}$ is assumed to be constant over time. We follow a sequential 
procedure, where we start from the actual employment across age groups and sectors, and forecast their employment in the next period using the models for predicting the survival and conditional growth rates and actual GDP growth. To compute the new aggregate employment we sum the forecasted employment among all sector-age groups. After that we forecast the new aggregate employment using the same procedure but instead use the forecasted employment and its distribution across age groups and sectors from the previous step. Following this procedure allows to forecast the evolution of aggregate employment as the function of start-up employment $S_{t}$ and GDP growth rates $Z_{t}$.

\section{Data}

In this section, we describe the data used for our analysis. We use quarterly data from the National Social Security Office (NSSO) of Belgium on all firms paying social security contributions during the period from 2003Q1 to 2020Q4. The data does not include self-employed people, because individual entrepreneurs report to the social security body for the self-employed, INASTI. However, it does include the people who work for self-employed. According to the estimate of the National Bank of Belgium, in the first quarter of 2017, there were 3.9 million domestic employees in Belgium, and according to the data, there were 3.5 million employees. Therefore, this administrative database covers around $90 \%$ of all paid employment in Belgium. ${ }^{2}$

The data include both, actual and full-time equivalent (FTE) number of employees per firm per quarter. ${ }^{3}$ We use the FTE number of employees as a proxy for firm size because it captures the actual creation and destruction of jobs by firms. The measure also avoids double counting of part-time employees, who work for multiple firms. We also exclude firms in the government sector (NACE 2-digit codes above 82 ), as these firms are typically heavily subsidized.

Figure 2 shows that the overall employment in Belgium declined by 3.7 and $19.3 \% \mathrm{Y}-\mathrm{O}-\mathrm{Y}$ in the first and second quarters of 2020, respectively. While in the second half of 2020, the employment partially recovered, the employment gap remained at 4.3 and $6.2 \% \mathrm{Y}-\mathrm{O}-\mathrm{Y}$ in the third and fourth quarters of 2020, respectively. Mature (ages 6+) firms and firms in distribution (NACE 44-56) are responsible for the majority of immediate job losses. In particular, mature firms represent $90 \%$ and the distribution sector represents $52 \%$ of short-term employment losses. The second-largest sector experiencing employment losses is the services sector (NACE 57-82) with 31\%. Before the start of the pandemic, all growth contributions were positive. While the health crisis affected the entire economy, the mature firms and the distribution sector were affected the most in absolute terms.

\footnotetext{
2 According to the estimate of the National Bank of Belgium, employees registered with the NSSO account for 85 percent of all paid employment in Belgium.

3 Similar to the financial crisis, FTE employment has declined much more sharply than the headcount employment. The total number of employees contracted by $1.4 \% \mathrm{Y}-\mathrm{O}-\mathrm{Y}$ at most during 2020 , while the FTE employment losses picked at $20 \%$. The difference between the two can be attributed to firms using furlough schemes in crisis times.
} 

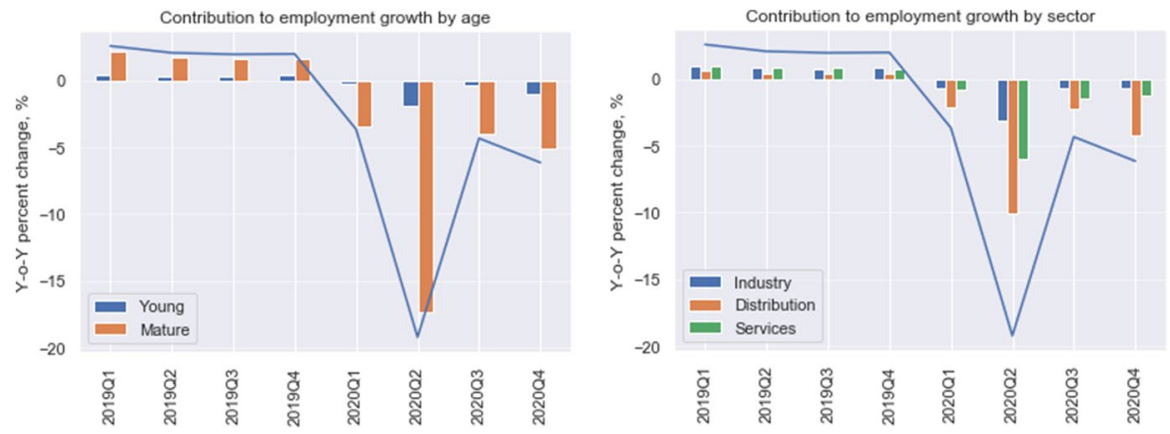

Fig. 2 Overall employment growth $(\mathrm{Y}-\mathrm{O}-\mathrm{Y})$ and its contributors by age and sector. The employment growth rate is plotted with the solid blue line. The left panel plots the employment growth contributions for young (ages 0-5) and mature (ages 6+) firms. The right panel plots the employment growth contributions for firms in the industry (NACE 1-40), distribution (NACE 44-56), and services (57-82) sectors
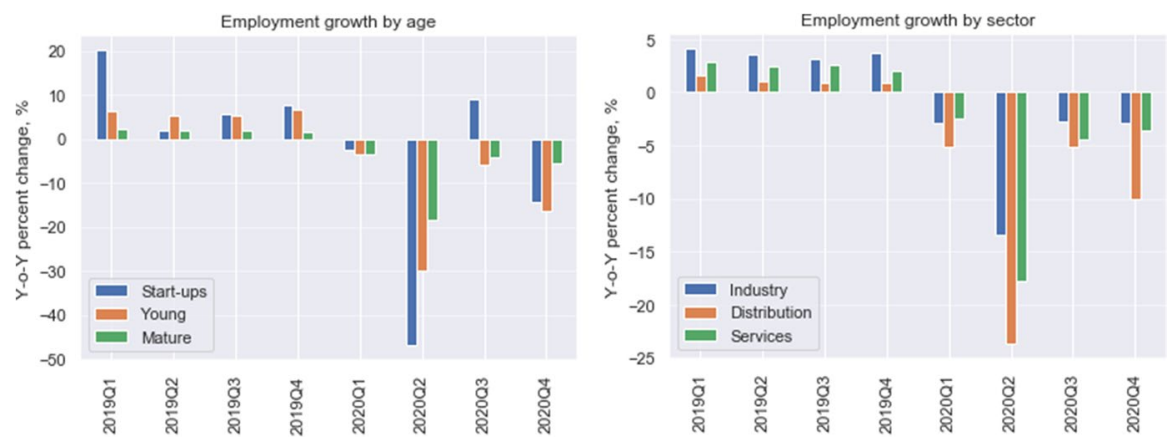

Fig. 3 Employment growth $(\mathrm{Y}-\mathrm{O}-\mathrm{Y})$ by age and sector. The left panel plots the employment growth of start-ups (age 0), young (ages 0-5), and mature (ages 6+) firms. The right panel plots the employment growth of the industry (NACE 1-40), distribution (NACE 44-56), and services (57-82) sectors

In relative terms, the first lockdown impacted the start-ups and the distribution sector the most. The left panel of Fig. 3 shows that the start-up and young firm employment declined by 47 and 30\% Y-o-Y, respectively, in the second quarter of 2020. At the same time, the mature firm employment declined by $18.5 \%$ Y-o-Y. By the end of 2020, the start-up and young firm employment remain affected the most at 14 and $16 \% \mathrm{Y}-\mathrm{o}-\mathrm{Y}$ employment decline in the fourth quarter of 2020.

The right panel of Fig. 3 shows that all sectors of the economy were adversely affected by the lockdown in 2020. The distribution and services declined by 24 and $18 \% \mathrm{Y}-\mathrm{o}-\mathrm{Y}$ by the end of the first half of 2020 , respectively. In the second half of 2020 , the distribution sector remains the most severely affected sector, in terms of employment, with an employment decline of $10 \% \mathrm{Y}-\mathrm{O}-\mathrm{Y}$ at the end of 2020. Also, the distribution sector has the highest entry and the lowest survival rates. Therefore, the missing generation of start-ups formed during the lockdown amplified the shortterm impact on the distribution sector through the life-cycle dynamics of incumbent firms. 
Fig. 4 The figure plots the evolution of the start-up employment. The empty circles plot the raw data measurements. The black solid line plots the trend component of the series

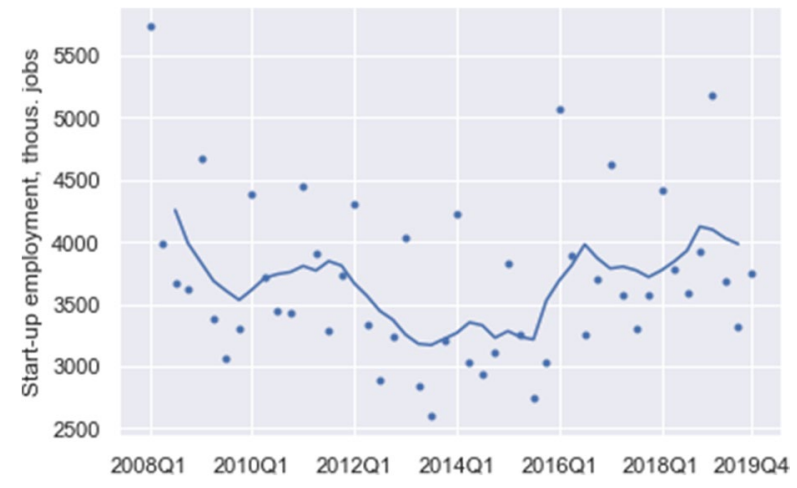

To estimate the dynamic framework we measure the evolution of the start-up employment, the sectoral composition of start-ups, and the sectors' age-specific survival rate and conditional growth rate over time. Since the data do not provide information on firm age explicitly, we infer firm entry based on the first appearance of a firm in the data set. Similarly, we infer firm exit based on the last appearance of a firm in the data set. We are also interested in measuring the employment of a "true" entry rather than the employment of a "spurious" entry, such as ID change of a firm, the breakup of a firm into two or more firms, the merger of two existing firms or acquisition of one firm by another. Geurts (2016) and Geurts and Van Biesebroeck (2016) show that such biases result in significant distortions of the size distribution of entering firms and of the estimates of the post-entry growth dynamics of firms. Therefore, we use the shares of "spurious" entrants by size (Table 2 in Geurts 2016) as probabilities to correct the age distribution of firms by probabilistically re-assigning the age of entering firms to $a=$ $6+$ based on their size.

To simplify the computations we make use of the result in Geurts and Van Biesebroeck (2016), where authors show for Belgium that within age cohorts firm growth is strictly increasing with the size until the age of 5 years, and afterward, it becomes independent of size. Therefore, we modify Eq. 3 to distinguish between the firms up to the age of 5 years, and afterward, we group the firms that are six years old or above under the " $6+$ " age group. The resulting startup employment is given in Fig. 4. The raw data plotted with empty circles indicate high cyclicality in the start-up employment. The trend component plotted as a solid line suggests that the start-up employment was declining until 2015 and stayed stable afterward.

The quarterly GDP growth rates are taken from the statistics website of the National Bank of Belgium and plotted in Fig. 5. The raw data is plotted with the empty circles and the trend of component of the series is plotted with the solid line. In the aftermath of the financial crisis of 2008 the GDP growth rate fell sharply $-2 \%$ and recovers quickly in the following years. After that, the trend component of the GDP growth rate fluctuates around $0.4 \%$ with a slight dip in 2013. For the model validation, we use the actual values of the GDP growth rate 
Fig. 5 The figure plots the growth rate of GDP in Belgium. The dots plot the raw data. The solid line plots the moving average of four quarters of the series

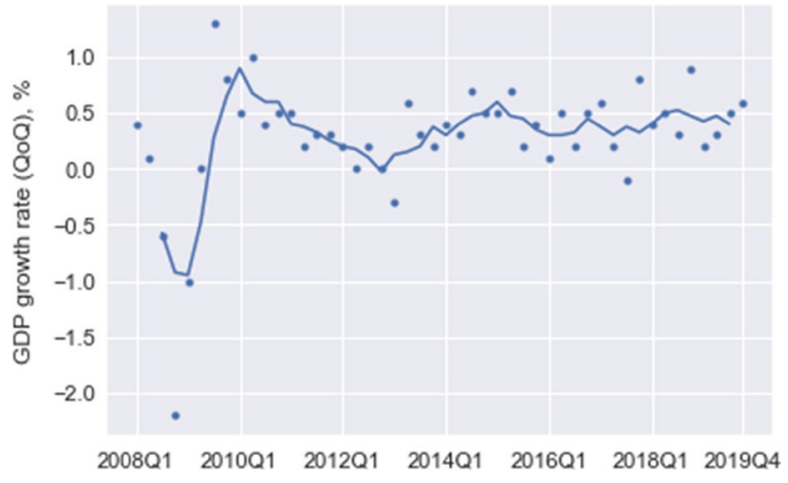

and start-up employment up to 2019Q4 as exogenous variables in simulation. For the forecasting period, we use the pre-COVID trend values of the GDP and startup employment as exogenous variables in simulation for the baseline case.

\section{Model validation}

In this section, we validate the model's forecasting ability. To this end, we backtest the model on the period from 2008Q1 to 2018Q4. We take the actual start-up employment and the GDP growth rate as given (exogenous) and predict the survival rate and the conditional employment growth rate of age cohorts within sectors using the machine learning models selected based on the cross-validation strategy and the exogenous variables. We aggregate the forecasted employment within sector-age cohorts to compute the aggregate employment forecast.

We start from the initial employment of 2008Q1 and compute the employment in the next quarter using the predicted values of the survival and conditional growth rates for that quarter. We repeat this cycle sequentially forecasting the employment until 2018Q4. In an ideal situation, the forecasted employment should exactly follow the actual employment. Figure 6 plots the actual and forecasted employment. The trend component of actual employment is plotted with the black solid line and the trend component of forecasted employment is plotted with the dashed red line. The forecasted employment closely follows the forecasted employment suggesting the high forecasting accuracy of the model. To quantify this accuracy, on average the margin of error is \pm 240 jobs within sector age cohorts.

Looking within industries, we see that the model performs better in certain industries better than in others. To illustrate this, we group firms into three broad sectors, industry (NACE 01-40), services (NACE 57-82), and distribution (44-56). Figure 7 plots the forecasted and actual employment by sector. While the margins of error within industry and services are comparable with the overall $( \pm 181$ jobs within industry age cohorts and \pm 247 jobs within services age cohorts), the distribution sector has a systematic over-prediction with the margin 


\section{The Aggregate Employment of Belgium}

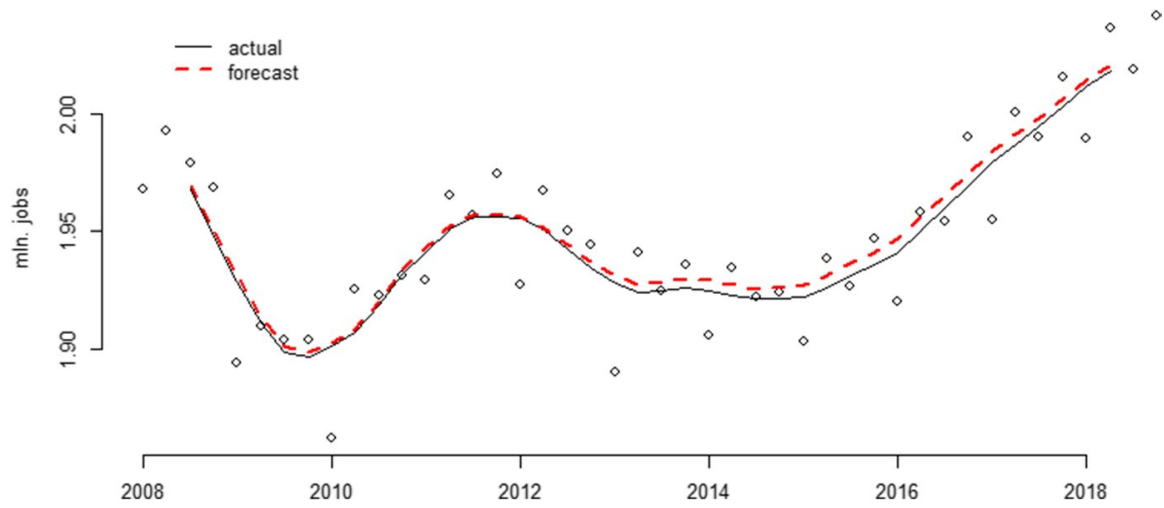

Fig. 6 The figure plots the actual and forecasted employment of Belgium for the period from 2008Q1 to 2018Q4. The empty circles plot the raw data. The black solid line plots the trend component of the actual raw data. The red dashed line plots the trend component of the forecasted employment
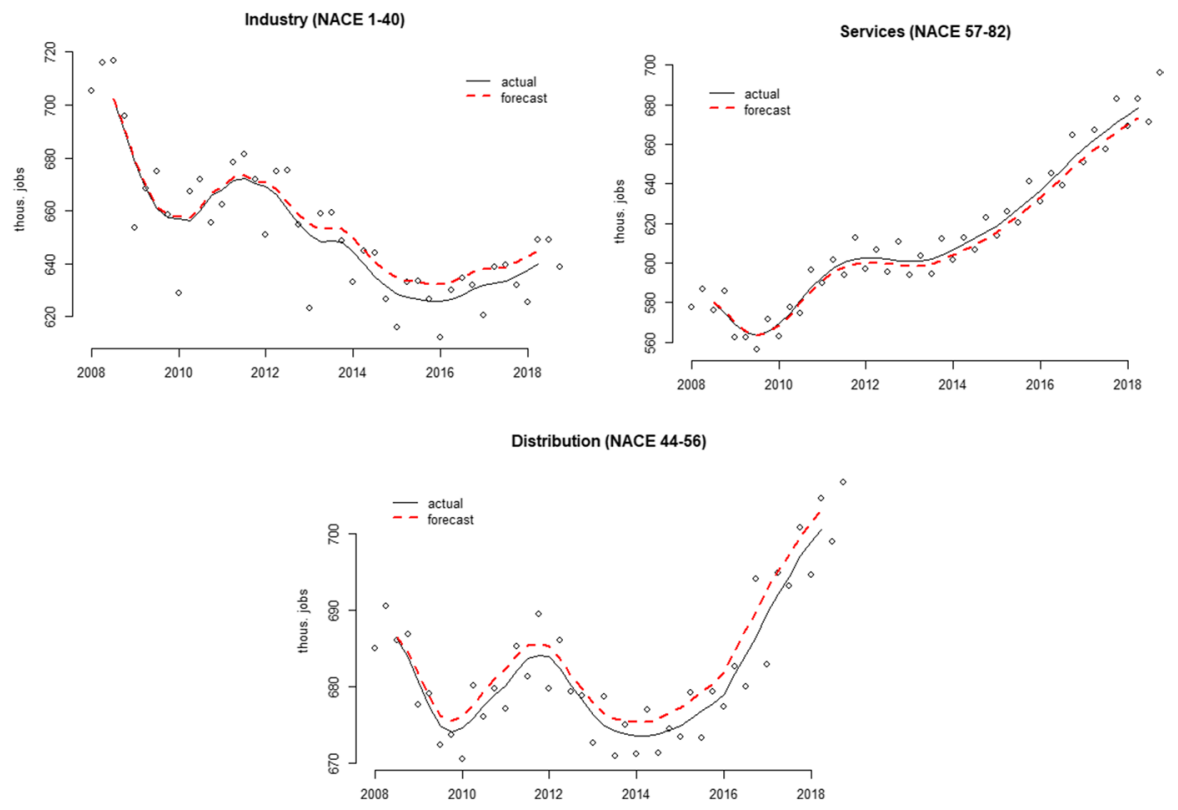

Fig. 7 The figure plots the actual and forecasted employment by sector of Belgium for the period from 2008Q1 to 2018Q4. The empty circles plot the raw data. The black solid line plots the trend component of the actual raw data. The red dashed line plots the trend component of the forecasted employment

of error of \pm 395 jobs within age cohorts. Karimov and Konings (2020) show that the distribution sector in Belgium has the lowest survival rate and the highest entry rate. The increased margin of error in distribution is driven by the volatility of incumbent firms. Foster et al. (2006) show that the retail trade sector of the 

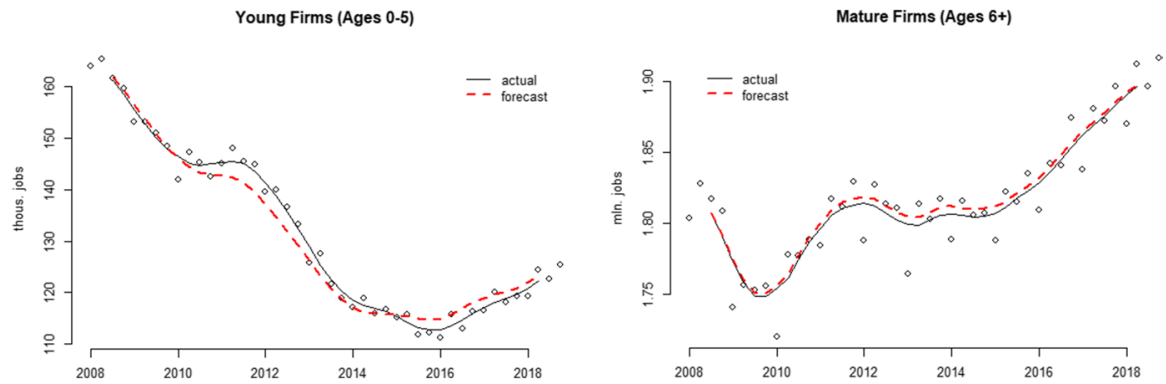

Fig. 8 The figure plots the actual and forecasted employment by age groups of Belgium for the period from 2008Q1 to 2018Q4. The empty circles plot the raw data. The black solid line plots the trend component of the actual raw data. The red dashed line plots the trend component of the forecasted employment

US in the 1990s was very different from manufacturing or services because of the intensive adoption of advanced information technology. Similarly, within age groups, Fig. 8 shows that the forecasted employment follows closely the actual employment.

While the forecasting accuracy of the model is not ideal, it is good enough to capture the evolution of aggregate employment for ten years without deviating from the actual employment significantly. This is a remarkable accuracy, given that the forecasted employment is being computed sequentially based on the forecasted values before that. It is important to keep in mind that the model overpredicts employment in distribution.

\section{Forecasting employment}

In this section, we use the forecasting model to estimate the impact of the lockdown on the employment of Belgium. To this end, we develop a scenario of how the start-up employment and the growth rate of GDP are affected during and after the lockdown. By looking at the differences between the two scenarios, we isolate the impact of the COVID-19 lockdown on employment in Belgium.

The impact is modeled relative to a baseline case as if there was no lockdown of the economy. In the baseline case, we assume that the start-up rate remained at its pre-lockdown level with seasonal fluctuations. Similarly, we assume that the growth rate of GDP remained at its pre-lockdown level with seasonal fluctuations and random noise components estimated from the data. In the lockdown case we assume that the start-up employment declined by 22, 45, 30, and $40 \%$ in Q1, Q2, Q3, and Q4 of 2020, respectively, relative to the baseline case. In the first two quarters of 2021, we assume the start-up employment remains at 70 and $80 \%$ relative to the baseline case. While this assumption may seem pessimistic, the latest data on firm entry with employment in Belgium suggest that start-up activity remains below the pre-pandemic level (15\% Y-o-Y in 
2020Q4). In addition, the development of new variants of the coronavirus creates additional uncertainty for business in 2021. Even in the US, a much more dynamic and entrepreneurial economy, ${ }^{4}$ the business applications with planned wages reach the pre-pandemic level only 40 weeks after the start of the crisis (Haltiwanger 2021).

We use the estimates of the National Bank of Belgium that the GDP of Belgium grew by $-3.3,-11.9,11.8$, and $-0.1 \%$ in Q1, Q2, Q3, and Q4 of 2020. In the first quarter of 2021, the economy grew by $0.6 \%$. The remaining GDP growth rates are left identical as in the baseline case. For both, the baseline and lockdown cases, we forecast the evolution of aggregate employment for the period from 2019Q4 to 2029 Q4.

The left panel in Fig. 9 plots the forecasted aggregate employment for two cases, the baseline (the black solid line) and lockdown (the dashed red line) scenarios. The right panel plots the employment gap as the difference between the lockdown and baseline cases. We see a sharp decline in employment peaking in Q1 of 2021 reaching around 40 thousand jobs. This gap starts to shrink with time reaching around 14 thousand jobs in 2025, but starts to grow again afterward reaching 26 thousand jobs in 2030 and seems to continue growing.

Looking at the employment gap across age groups in Fig. 10, we see that it is the mature firms (ages $6+$ ) that are driving the employment gap in the short term. They account for 30 out 40 thousand of lost jobs. Young firms (ages 0-5) account only for 10 thousand jobs and the missing generation of start-ups account only for half of it. The majority of job losses in the short are primarily driven by incumbent firms.

Looking at the employment gap across sectors, we see that it is the services sector that losses the most jobs in the long run. Figure 11 plots the forecasted employment gap by sector. In the short term, the industrial sector is affected the most accounting for 20 thousand lost jobs in 2021. In the long term, the employment gap in the industrial sector almost fully recovers by 2025 . On the other hand, services are affected the most in the long term with the employment gap reaching 25 thousand jobs by 2030 and continuing to grow afterward. The differences between industry and services are driven by low start-up and employment growth rates in the industry, and high start-up and employment growth rates in services. Therefore, the missing generation of start-ups creates a persistent and growing employment gap in services. While the distribution sector has high entry rates as well, it also has the highest exit rates among sectors. Therefore, the lack of strong post-entry growth dynamics in distribution does not allow the missing generation of start-ups to leave long-lasting effects.

To illustrate the role of the missing generation of start-ups, we run the same simulation under the assumptions of a decline in GDP, but in which the start-up rate of new firms remains the same as in the baseline case. The left panel in Fig. 12 plots

\footnotetext{
4 IMD's World Competitiveness Ranking (2015, 2016, 2017): USA (1st, 3rd, 4th) vs. Belgium (23rd, 22nd, 23rd); WEF's Global Competitiveness Report (2016-2017): USA (3rd) vs. Belgium (17th), World Bank's Ease of Doing Business (2017): USA (8th) vs. Belgium (42nd).
} 

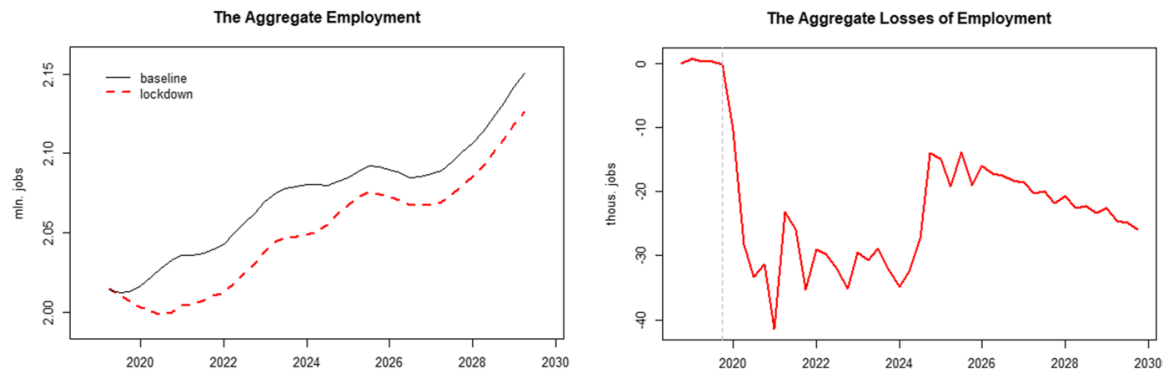

Fig. 9 The figure plots the forecasted aggregate employment for the lockdown and baseline cases. On the left panel, the black solid line plots the aggregate employment for the baseline case. The red dashed line plots the aggregate employment for the lockdown case. On the right panel, the red solid line plots the employment gap due to lockdown

the new forecasted employment gap. While the employment gap remains substantial, the magnitude of the gap decreases by almost 50\% (from 26 thousand jobs to 14 thousand jobs). This difference is due to the post-survival growth rate of some start-ups which are doing well enough to offset the employment losses of incumbent firms. The right panel of Fig. 12 shows that young firms create more jobs relative to the baseline case and therefore help to reduce the employment gap due to a recession in 2020.

Recent literature highlights the positive contribution of young and small firms to net job creation during business cycle fluctuations. In particular, Pugsley and Şahin (2019) show that young firms in the US grow faster during economic recoveries than their mature counterparts. Moscarini and Postel-Vinay (2012) show that small firms on the net create proportionately more jobs relative to large firms when unemployment is above trend. Moreover, the initial conditions of firms at the start-up phase also affect the post-entry growth dynamics of these firms (Sedláček and Sterk 2017; Sterk et al. 2021). Therefore, the impact of the missing generation of start-ups is exacerbated by the lost potential of these firms. Sedláček (2019) highlights that the missing generation of firms during the financial crisis of 2008 in the US left a persistent employment dent.
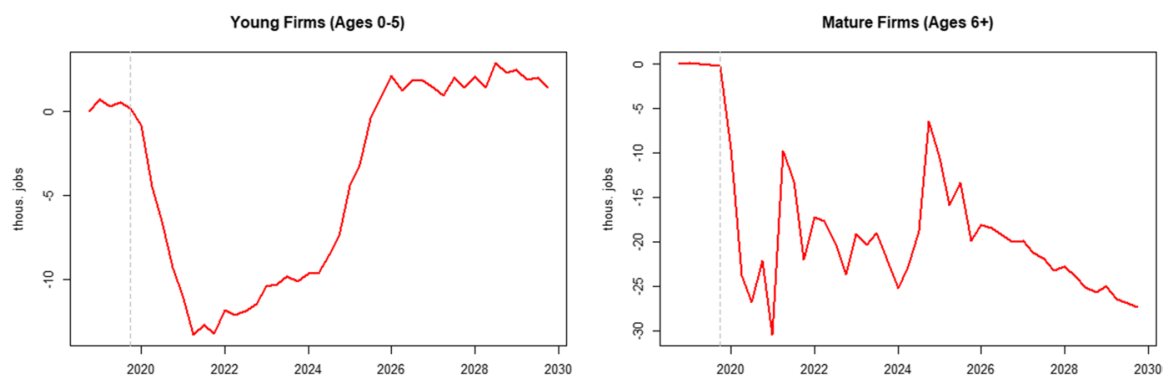

Fig. 10 The figure plots the forecasted employment gap in Belgium by age group for the period from 2019Q1 to 2029Q4 

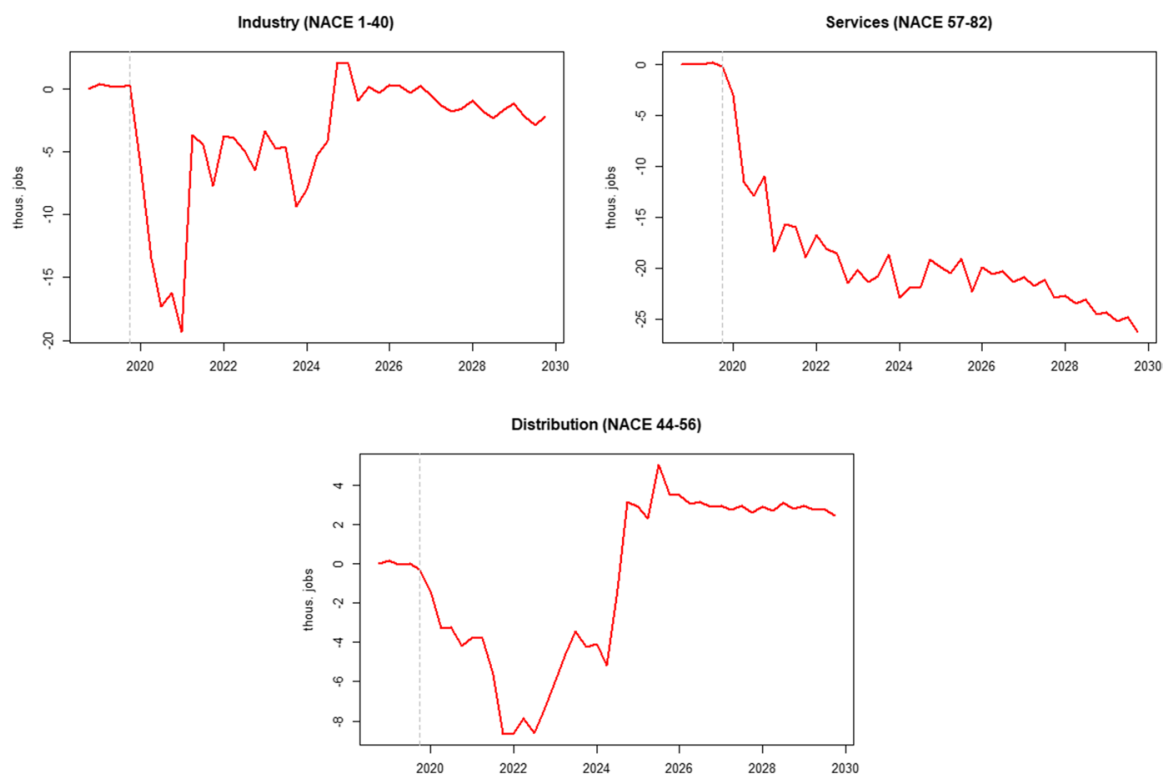

Fig. 11 The figure plots the forecasted employment gap by sector of Belgium for the period from 2019Q1 to 2029Q4

\section{Conclusion and policy implications}

In this paper, we show how the COVID-19 lockdown affects the aggregate employment of Belgium. The lockdown has had a major impact on the economy, which will result in massive job loss, depending on the potential rebound of the economy and on how entrepreneurship is being affected. In the current simulation, we estimate a total job loss of 41,000-42,000 in the short run, but even a decade later an employment gap of 26,000 jobs is expected to remain. Almost half of the employment gap is due to a missing generation of start-ups during the lockdown. This has permanent effects. The fact that there are fewer start-ups implies that there is a lower chance
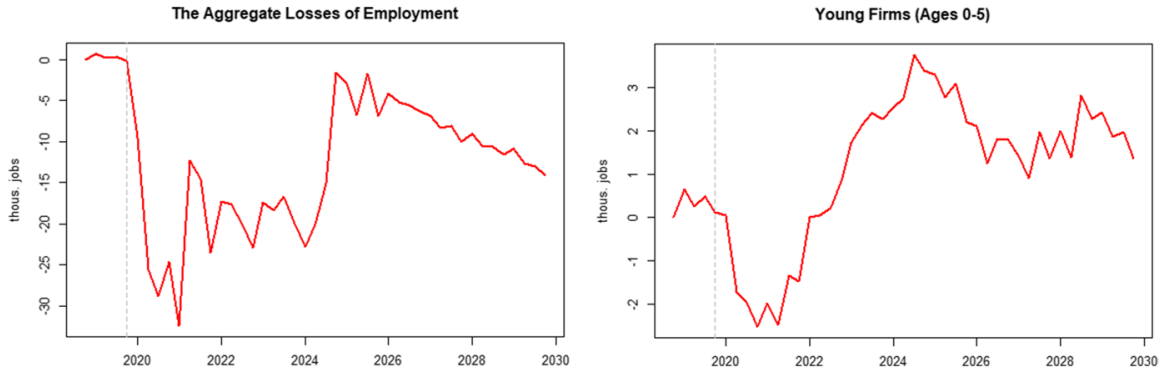

Fig. 12 The figure plots the forecasted aggregate employment for the baseline case and the lockdown with start-ups case, in which the effect of lower GDP is only taken into account, while the start-up rates remain unaffected. The black solid line plots the baseline case. The red dashed line plots the lockdown case with start-ups 
that among these start-ups one or more high growth firms emerge, which become dominant.

To this end, we develop a machine learning-based approach to forecast the aggregate employment taking into account the shifts in the firm age distribution and the sectoral composition of the economy. The approach allows us to incorporate expectations about the growth of the economy and understand the role of start-ups for aggregate employment. While this is not a structural model, it incorporates the literature on firm dynamics and business cycle fluctuations into a machine learning model based on historical data. Therefore, the obtained results are based on real relationships observed in the data and sound economic intuition.

The policy implications are clear. Most of the support measures have been targeted towards supporting existing companies. While it is probably a good thing to save healthy companies, it comes at a cost of providing a soft budget constraint to inefficient companies who should have left the market under normal circumstances. Hence the process of creative destruction has been disturbed which is likely going to have an impact on productivity growth, which was already low. This process of creative destruction is mainly driven by new start-ups and young companies.

This suggests that policy should be targeted to stimulate entrepreneurship and young firms. Obvious measures include a reduction of regulation affecting new firm entry and entrepreneurs, government bank guarantees for young firms and start-ups, special start-up subsidies, reductions of social security contributions for start-ups hiring workers, and a reduction of corporate taxes. While there is a risk that incumbent firms may try to benefit from these policies by restructuring, monitoring the recipients of these benefits is important for policy evaluation.

Acknowledgements This work has benefited from the presentations at VIVES. Financial support of the "Methusalem" grant established by the Flemish government is gratefully acknowledged. Also, we want to thank Werner Roeger and participants of the EIIW digital workshop on "How will COVID-19 affect an already fragile global economy?" for their comments and discussion.

\section{References}

Acemoglu D, Cao D (2015) Innovation by entrants and incumbents. J Econ Theory. https://doi.org/10. 1016/j.jet.2015.01.001

Aghion P, Blundell R, Griffith R, Howitt P, Prantl S (2009) The effects of entry on incumbent innovation and productivity. Rev Econ Stat. https://doi.org/10.1162/rest.91.1.20

Decker RA, Haltiwanger JC, Jarmin RS, Miranda J (2017) Decling dynamism, allocative efficiency, and the productivity slowdown. Am Econ Rev. https://doi.org/10.17016/FEDS.2017.019

Decker RA, Haltiwanger J, Jarmin RS, Miranda J (2016) Declining business dynamism: what we know and the way forward. Am Econ Rev. https://doi.org/10.1257/aer.p20161050

Dent RC, Karahan F, Pugsley B, Şahin A (2016) The role of startups in structural transformation. Am Econ Rev. https://doi.org/10.1257/aer.p20161053

Duarte M, Restuccia D (2010) The role of the structural transformation in aggregate productivity. Quart J Econ. https://doi.org/10.1162/qjec.2010.125.1.129

Foster L, Haltiwanger J, Krizan CJ (2006) Market selection, reallocation, and restructuring in the U.S. retail trade sector in the 1990S. Rev Econ Stat 88:748-758. https://doi.org/10.1162/rest.88.4.748

Geurts K (2016) Longitudinal firm-level data: problems and solutions. Small Bus Econ. https://doi.org/ $10.1007 / \mathrm{s} 11187-015-9693-6$ 
Geurts K, Van Biesebroeck J (2016) Firm creation and post-entry dynamics of de novo entrants. Int J Ind Organ. https://doi.org/10.1016/j.ijindorg.2016.08.002

Haltiwanger J (2021) Entrepreneurship during the COVID-19 pandemic: evidence from the business formation statistics. NBER working paper

Haltiwanger J, Jarmin RS, Miranda J (2013) Who creates jobs? Small versus large versus young. Rev Econ Stat. https://doi.org/10.1162/REST_a_00288

Hastie T, Tibshirani R, Friedman J (2009) The elements of statistical learning the elements of statistical learning data mining, inference, and prediction. Springer series in statistics, 2nd edn. Springer, Berlin. https://doi.org/10.1007/978-0-387-84858-7

Karimov S, Konings J (2020) The start-up gap and jobs. Small Bus Econ. https://doi.org/10.1007/ s11187-020-00395-Z

Konings J, Yergabulova A (2021) Firm growth in times of crisis (discussion paper). https://cepr.org/ active/publications/discussion_papers/dp.php?dpno=16072

Lawless M (2014) Age or size? Contributions to job creation. Small Bus Econ. https://doi.org/10.1007/ s11187-013-9513-9

Moscarini G, Postel-Vinay F (2012) The contribution of large and small employers to job creation in times of high and low unemployment. Am Econ Rev. https://doi.org/10.1257/aer.102.6.2509

Pugsley BW, Şahin A (2019) Grown-up business cycles. Rev Financ Stud. https://doi.org/10.1093/rfs/ hhy063

Sedláček P (2019) Lost generations of firms and aggregate labor market dynamics. J Monet Econ. https:// doi.org/10.1016/j.jmoneco.2019.01.007

Sedlacek P, Sterk V (2020) Startups and employment following the COVID-19 pandemic: a calculator. CEPR discussion papers

Sedláček P, Sterk V (2017) The growth potential of startups over the business cycle. Am Econ Rev. https://doi.org/10.1257/aer.20141280

Sterk V, Sedláček P, Pugsley B (2021) The nature of firm growth. Am Econ Rev 111(2):10. https://doi. org/10.1257/AER.20190748

Publisher's Note Springer Nature remains neutral with regard to jurisdictional claims in published maps and institutional affiliations. 